\title{
Article
}

\section{Are dental professionals more likely to consume sweet snacks, over savoury snacks in the workplace?}

\author{
Hassan, A, Hamilton, J and Morris, Matthew Kendrick \\ Available at http://clok.uclan.ac.uk/25568/ \\ Hassan, A, Hamilton, J and Morris, Matthew Kendrick (2018) Are dental \\ professionals more likely to consume sweet snacks, over savoury snacks in \\ the workplace? British Dental Journal, 225 (11). pp. 1019-1022. ISSN 0007- \\ 0610
}

It is advisable to refer to the publisher's version if you intend to cite from the work. http://dx.doi.org/10.1038/sj.bdj.2018.1034

For more information about UCLan's research in this area go to http://www.uclan.ac.uk/researchgroups/ and search for <name of research Group>.

For information about Research generally at UCLan please go to http://www.uclan.ac.uk/research/

All outputs in CLoK are protected by Intellectual Property Rights law, including Copyright law. Copyright, IPR and Moral Rights for the works on this site are retained by the individual authors and/or other copyright owners. Terms and conditions for use of this material are defined in the policies page.

\section{CLoK}

Central Lancashire online Knowledge www.clok.uclan.ac.uk

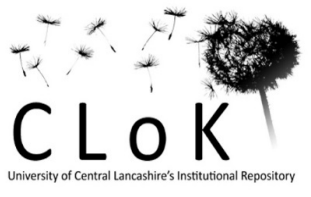




\title{
Are Dental Professionals more likely to Consume Sweet Snacks, over Savoury Snacks in the workplace? Authors Amaar Hassan, Jessica Hamilton, Matthew Morris
}

\author{
Amaar Hassan \\ im currently studying an online course in health research at aberdeen so you could put their \\ university, or were i work \\ University of Aberdeen \\ DCT2 Oral Maxillofacial Surgery and Orthodontics, Dumfries and Galloway Royal Infirmary \\ amaar.hassan1@nhs.net \\ Jessica Hamilton \\ StR Special Care Dentistry \\ Newcastle Dental Hospital \\ Jessica.Hamilton2@nhs.net \\ Matthew Morris \\ University of Central Lancashire MSc Periodontics \\ mkmorris@uclan.ac.uk
}

\section{Abstract}

Introduction It has been speculated, but never been formally researched that dental professionals are the most experienced team for consuming sweet snacks. This is despite many undergraduate dental courses reinforcing the traditional theory that patients should be advised to avoid snacking on foods which are likely to contain sticky sugars that cause tooth decay.

Design This was a prospective study, where several dental clinics across England were provided with sweet and savoury snacks during a normal working day. Staff members were then covertly observed, and their snacking patterns assessed.

Results The average time it took for a sweet snack to be opened and consumed in a dental environment was 3.6 minutes, compared to 7.2 minutes for savoury snacks.

Dentists were more likely to be seen eating sweet snacks, as opposed to savoury snacks. $36.7 \%$ of dentists were observed eating savoury snacks, compared to $44.1 \%$ eating sweet snacks. Other staff members, including administration and cleaning staff, were the most likely representative group to be seen eating any snacks under observation. 
Discussion and Conclusions The rate at which sweet snacks were opened and consumed were at Olympic level amongst dental staff. The recommendations are that the dental team revisit the Prevention Toolkit for Delivering Better Oral Health and book into their local practice for a dental check-up.

\section{Introduction}

Advice is given according to 'Delivering better oral health: an evidence-based toolkit for prevention' [1]. Non-sticky snacks such as rice cakes, hummus, bread and carrot sticks are preferred to snacks coated in sugar, such as chocolates and biscuits. The reasons for this are to have a balanced, healthy diet and for the prevention of tooth decay. An article has recently been published confirming that toothbrushing alone is not enough to prevent tooth decay in children under the age of five [2].

Anecdotally, from peer group meetings, a recurring theme of discussion raised amongst dentists is the frustration of finding new cavities at recall appointments, having recently completed extensive treatment. In one case 4 new cavities were identified following the restoration of 12 cavities and the extraction of 3 teeth at the last treatment plan. On enquiry as to whether this individual had adapted positive diet or lifestyle changes following the rigorous diet analysis and preventative advice delivered by the oral healthcare nurse in the practice, the patient proudly reported they had switched from cola drinks to "lemon flavoured fizzy water". On further investigation, this was later identified as "Fanta Lemon". We wondered which snacks dental professionals preferred to consume during lunchtime, after having a demoralising morning of patient recalls, such as the individual described above.

A sporadic literature search for "survival", "times"," sweet", "savoury", "snacks", "chocolates", "professionals" came back with just one relevant article [3], suggesting data for dental professionals' sweet taste buds has not been well documented or researched. The relevant article highlighted that boxes of chocolates are more likely to be consumed in hospitals by non-clinical staff, followed by nurses and then doctors. Having expanded on this relevant article, we wondered whether dental professionals were the role-models for snacking in the work place, and if there was a difference in consumption habits of sweet and savoury snacks. We have obtained data from multiple dental specialities and geographical locations.

\section{Method}

This was a prospective study; data was collected from various departments, including dental hospital emergency clinic, oral and maxillofacial surgery department, NHS practice and private practices. The inclusion criteria were all staff working at dental practices, including dentists, nurses, receptionists and cleaners that ate the snacks provided by our researchers, during lunch hour. 
We agreed that approaching individuals for consent prior to the study may have caused bias to the data.

- Ethical approval and consenting of participants pre-snack distribution were not deemed as necessary, as it was the individual team member's choice as to whether they opted to eat the snack food or not.

- Although it was tempting to 'name and shame', it was decided to keep the participants anonymous due to the well documented GDPR laws.

- We discussed that the researchers must divulge the research and gain consent to publish the data, after the study had been completed.

- If anybody rejected to the data being used, then it would be removed from the study.

A total of 11 centres were involved in the study, including 53 dentists, 74 nurses, and 17 other staff members. Participating dental centres were nationwide, including Yorkshire, the North, North West, Midlands and London. One practice is fully private, one was based at a dental hospital and another at a maxillofacial unit.

For this article, the two snack types are referred to as "sweet" or "savoury". Some savoury snacks contain 'hidden sugars' therefore it was important that during the data collection that we did not refer to any snacks as 'sugar' or 'non-sugar' but rather sweet snacks which contain sticky sugars and are more likely to cause tooth decay.

A 'researcher' was planted in each staff room who placed a savoury snack, such as rice cakes or crackers, and a sweet snack of something sticky or chocolatey (figure $1 \mathrm{a}$, and b). These foods were then closely monitored for speed of package opening and feasting of contents, and then a comparison was made of team member consumption habits. We prioritised the data on how fast snacks were opened, rather than how quickly they were scoffed (although we still published the data on the time for total ingestion of each snack type). Rationale behind this was as we thought certain snacks may take longer to devour than others, particularly if they had different numbers of servings. We also appreciated that not all the practices were able to obtain the same snacks from their local supermarket and we wanted to make the research design simple and easy. For example, it was likely that the local maxillofacial and oral surgery department (OMFS) resides at a local hospital, and this usually has a local newsagent (WHSmith) that uses elevated pricing to exploit poorly patients and fatigued staff members when purchasing essentials. Local supermarkets in Yorkshire tended to sell more cheeses, and the North West had an array of Sunday roast dishes such as bubble and squeak and toad in the hole. We found it very difficult to find any snacks at all in local supermarkets up north, as the main consumer item appeared to be real ale.

It was agreed by our expert panel of statisticians, that the percentage of people being seen eating snacks (for example, eight out of nine dentists seen eating sweet snacks) was easier to observe and interpret, than the total amount of food eaten by each professional (for example, $100 \%$ of the muffins being seen eaten by dentists). This was because there were a 
different total number of dentists, nurses and other healthcare professionals across each centre, and we appreciate that some individuals may have eaten more snacks than others.

\section{Results}

Researchers recorded the data in table form which is interpreted in figure 2.

- Sweet snacks were opened significantly quicker, on average after 3.6 minutes

- Savoury snacks were on average opened after 7.2 minutes.

- General dental practices were faster at opening snacks on average, as opposed to dental hospitals and OMFS departments, who preferred to firstly weigh up the risks versus benefits of snack consumption.

- Dentists preferred to eat sweet snacks over savoury snacks, with $44.1 \%$ of dentists observed eating sweet snacks compared to $36.7 \%$ of dentists eating savoury snacks. This was a greater preference in sweet over savoury in comparison to any other dental staff members.

- Nurses were less likely to eat sweet snacks (42.4\%) than savoury snacks (55.1\%).

- Other Healthcare professionals were the highest group of individuals to eat any snacks sweet snacks (60.6\%) and savoury snacks (55.5\%)

The speed in which boxes of savoury snacks were first opened is compared to the speed in which sugar snacks are first eaten (see figure 3, data represented as a line graph).

- The North and Yorkshire appeared to take significantly longer to pursue savoury snacks, preferring to divulge into the sweet sticky substances first.

Figure 4 visualises dentist's preferences to eat sweet snacks, compared to nurses, by displaying a pie chart (no pun intended).

\section{Discussion}

We have advised for anyone that has any other concerns about the research design or data collection, that it is unlikely this article is ever going to be the turning point of dentistry. This item being published as humour and hopefully stands in agreement of others that the study is taken light-heartedly and is not intended to be published to cause offense or confrontations between specialities.

One potential drawback of the study design, which has already been discussed in the method, was that different snacks were used in various cities. Despite this, we could still use the data to compare if the savoury snacks were preferred when given a choice and how fast they were being opened. 
We understood that the researcher was concealed, and this may limit their ability to accurately monitor and feedback the total amount of crumbs entering each orifice. Therefore, we agreed that the observations should be kept during lunch hour only. Statistical research from Dental Public Health could argue that consuming sweet and savoury snacks during lunch is technically legal, according to the Stephan curve, as it is during a 'main meal' time. We would argue that the Stephan curve takes 20 minutes for bacteria to stop producing acid; therefore, if people are eating snacks after their main meal then it would still be considered as "grazing".

\title{
$\underline{\text { Awards }}$
}

Figure 5 is a table illustrating the prizes awarded to participating centres, which helped to provide a discussion between the different geographical locations and specialities. Although Midlands had indeed won the prevention toolkit award, we felt that the researcher had not followed the guidelines regarding providing a savoury snack such as rice cakes or crackers. We felt that their choice of savoury food (see figure 6) was one of the main reasons why individuals chose to start on the savoury snacks first, rather than sweet. We attributed the cause of this data and named it the 'the dominoes effect' for causing bias.

\section{Conclusions}

This article demonstrates that dental staff are clearly competent in the art of snacking and preference is shown for opening sweet snacks over savoury. Dentists are amongst the worst team members for prioritising sweet snacking. Future studies could investigate types of lunch foods dental staff were bringing and whether snacking habits might be influenced by diets shared by spouses and family members. We recommend dental check-ups for all staff members and we will gladly receive any thanks for the diagnosis and treatment of any previously undiagnosed caries after reading this article.

Acknowledgements: Asfa Mughal, Chirag Patel, Dary Jones, Raheel Aftab, Rosie Moss, William Aspinall

\section{Appendices}

\author{
Figure 1 a
}

\section{Example of sweet snack used}




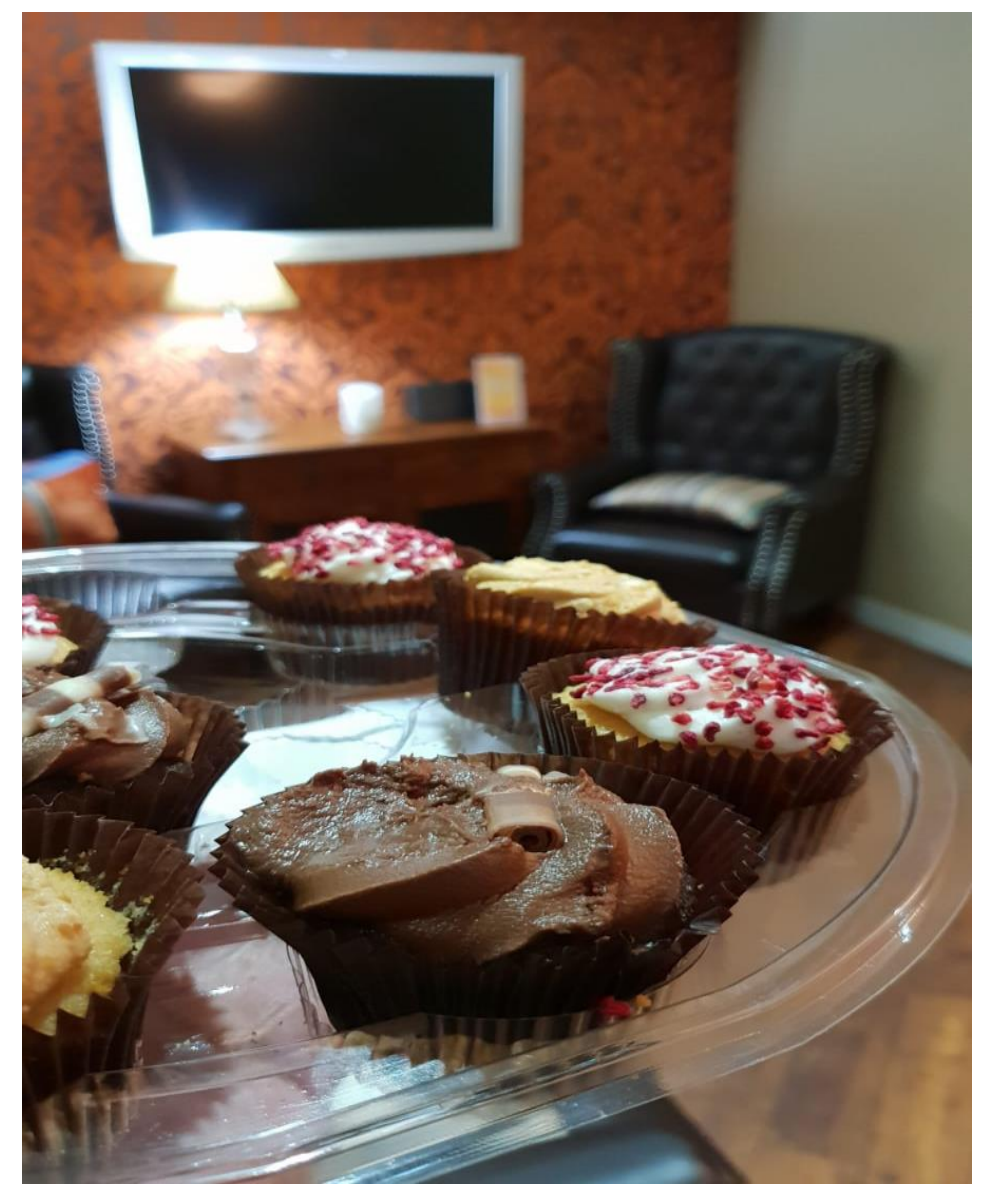

Figure $1 \mathrm{~b}$

Example of a savoury snack used 


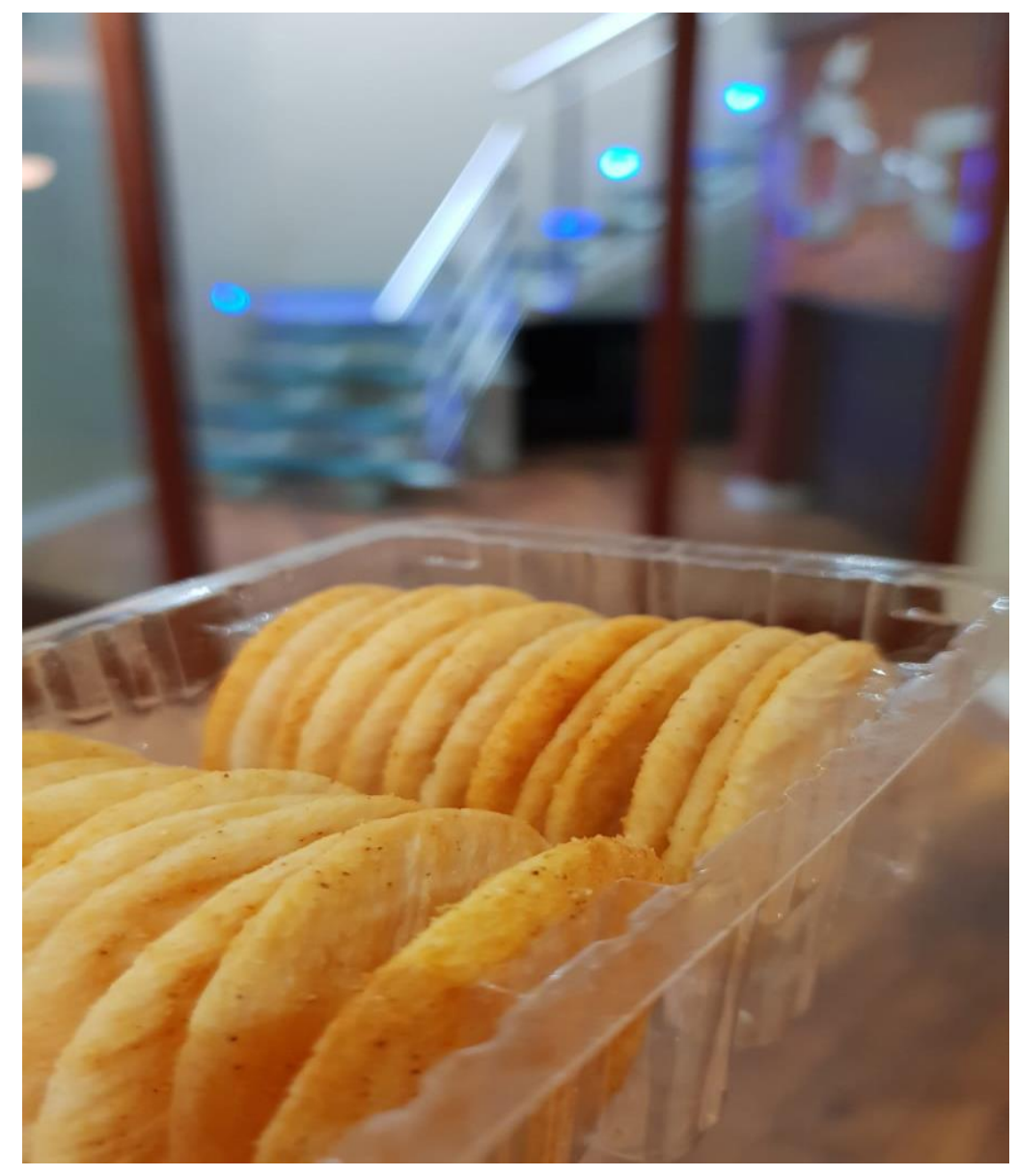

Figure 2

Data interpreted from the researcher's observations 
Total Number of Practices Involved

total dentists

total nurses

total other

Average total time savoury snack consumed (minutes)

Average total time sweet snack consumed (minutes)

Average savoury snack first opened (minutes)

Average savoury snack first opened (minutes)

Dentists present eating savoury snacks (percentage)

Nurses present eating savoury snacks (percentage)

Other healthcare profesisonals present eating savoury snacks (percentage)

Dentists present eating sweet snacks (percentage)

Nurses present eating sweet snacks (percentage)

Figure 3

\section{Line graph to compare time taken before snacks were opened}

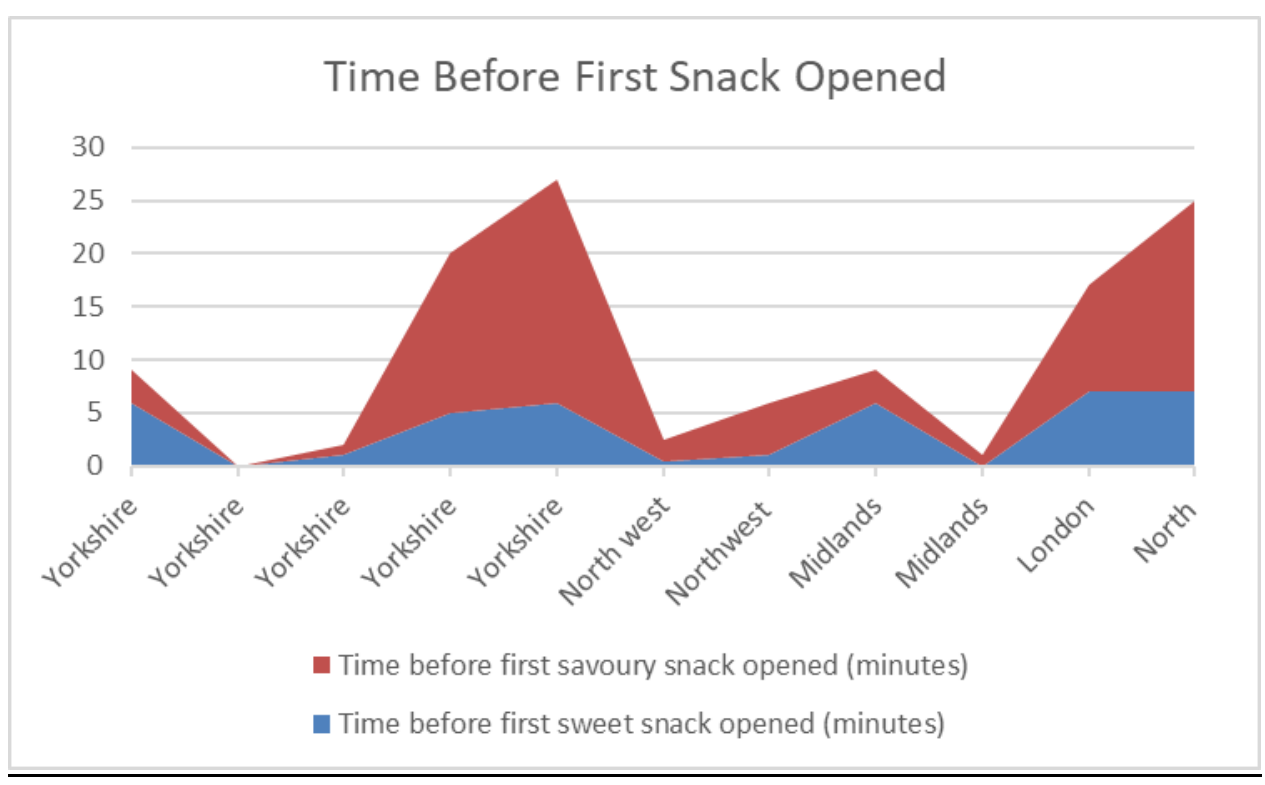


Figure 4 a

Pie chart of nurse's preference to sweet and savoury snacks

Percentage of Nurses Eating Snacks

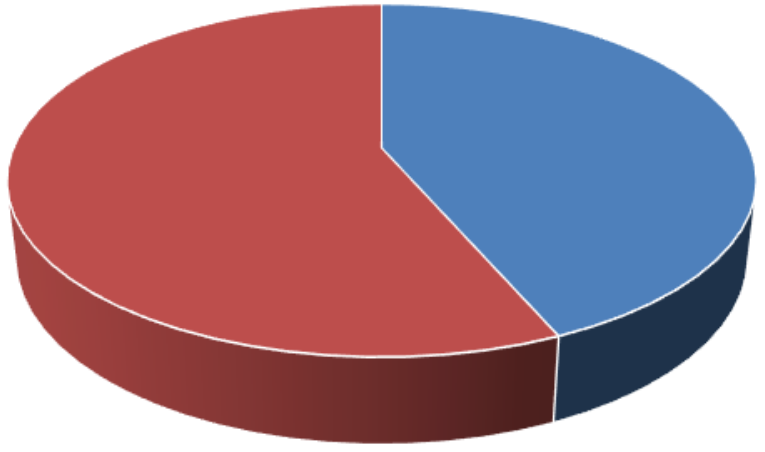

- percentage of nurses present eating sweet snacks

- percentage of nurses present eating savoury snacks

Figure 4b

Pie chart of dentist's preference to sweet and savoury snacks 
Percentage of Dentists Eating Snacks

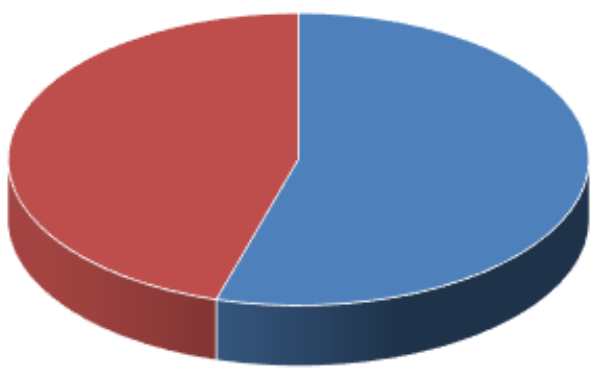

- percentage of dentists pr esent eating sweet snacks

- percentage of dentists present eating savoury snacks

\section{Figure 5}

\section{Awards list}

\begin{tabular}{|l||l||}
\hline Awards & \\
\hline Sweet Tooth. Most likely to prefer sweet snacks & Dentists \\
\hline Prevention Toolkit Award. Most likely to open savo ury snacks over sweet & Midlands \\
\hline Fast Hands. Quickest region for opening snacks & Northwest \\
\hline Fast Hands. Quickest speciality for opening snacks & GDPs \\
\hline Grazers. Speciality most likely to snack continuously & Dental Hospitals \\
\hline Grazers. Region most likely to snack continuously & North \\
\hline Party Spoiler. Staff most likely to be seen eatingall the snacks & Other Healthcare \\
\hline
\end{tabular}

Figure 6

\section{Savoury snack chosen by midlands}




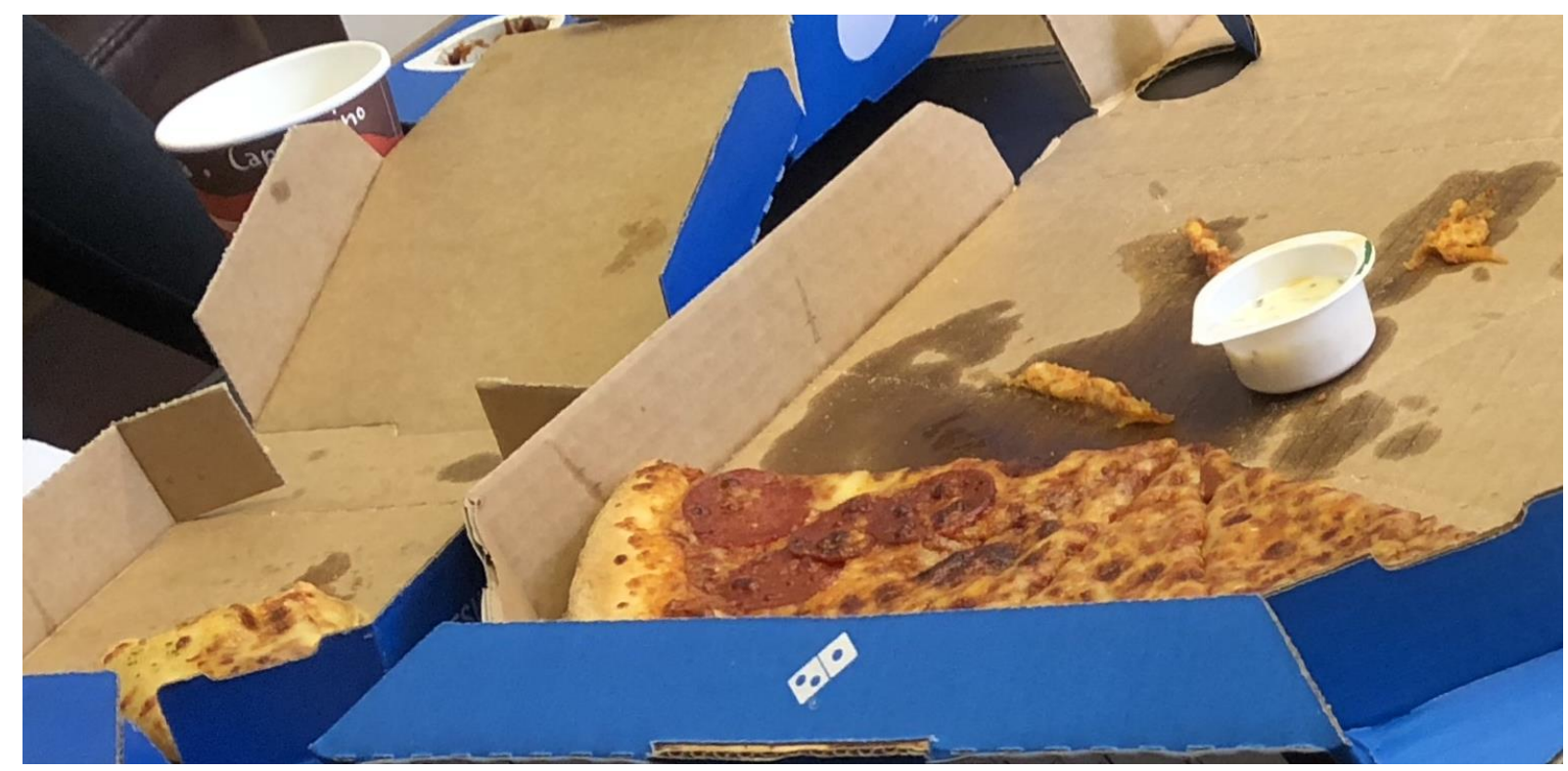

\section{References}

[1] Public Health England (2014). Delivering better oral health: an evidence-based toolkit for prevention. 12 June 2014. www.gov.uk/government/publications/delivering-better-oralhealth-an-evidence-based-toolkit-for-prevention (Accessed on 30/08/2018).

[2] Skafida V \& Chambers S (2017) Positive association between sugar consumption and dental decay prevalence independent of ora lhygiene in pre-school children: a longitudinal prospective study. Journal of Public Health. https://academic.oup.com/jpubhealth/advancearticle/doi/10.1093/pubmed/fdx184/4781590. (Accessed on 30/08/2018)

[3] The survival time of chocolates on hospital wards: covert observational study (2013) Parag R Gajendragadkar, Daniel J Moualed, Phillip L R Nicolson et al. BMJ 2013;347:f7198 https://www.bmj.com/content/347/bmj.f7198. (Accessed on 30/08/2018) 